\title{
EFEKTIVITAS PENGOLAHAN AIR LIMBAH DI RUMAH SAKIT UMUM MUSLIMAT KABUPATEN PONOROGO TAHUN 2015 (PENURUNANKADAR COD, AMONIAK, TSS, PHOSPHAT, DAN pH).
}

\author{
Galih Hersandya Yudha, Sigit Gunawan, Trimawan Heru Wiyono
}

\begin{abstract}
ABSTRAK
Menurut hasil pemeriksaan parameter kimia dan fisika limbah cair RSU Muslimat di laboratorium Balai Besar Teknik Kesehatan Lingkungan dan Pengendalian Penyakit (BBTKLPP) Surabaya bulan September 2013 kandungan parameter kimiaCOD 82,4 mg/l, Ammoniak sebesar 0,0940 mg/l, TSS sebesar $9 \mathrm{mg} / \mathrm{l}$, Phosphat sebesar 9,35 mg/l, pH sebesar 7,5. Data ini menunjukkan bahwa parameter Phosphat dan COD melebihi nilai baku mutu PERGUB JATIM No. 72 Tahun 2013 Tentang Baku Mutu Air Limbah Bagi Kegiatan Rumah Sakit.

Jenis penelitian ini adalah deskriptif yaitu satu penelitian yang dilakukan dengan melakukan deskripsi mengenai fenomena yang di temukan baik berupa faktor resiko maupun hasil. Dalam penelitian ini pengambilan sampel dilakukan selama lima hari berturut-turut dengan volume 2 liter per sampel. Jumlah keseluruhan sampel adalah 70 sampel dengan pembagian sampel yaitu sampel inlet 35 sampel dan sampel outled 35 sampel. Teknik pengambilan sampel menggunakan teknik integrated sampel dimana sampel gabungan yang di ambil secara terpisah dengan volume yang sama.

Berdasarkan hasil penelitian Efektifitas kerja instalasi pengolahaan air limbah rumah sakit umum Muslimat Ponorogo diketahui hasil pemeriksaan parameter CODpada outlet instalasi pengolahan air limbah sebesar 182,96 mg/l dan parameterammoniak sebesar $1,3 \mathrm{mg} / \mathrm{l}$, TSS sebesar $61,6 \mathrm{mg} / \mathrm{l}$, Phosphat sebesar $4,74 \mathrm{mg} / \mathrm{l}$ dan $\mathrm{pH}$ sebesar 7 . Dan dari hasil perhitungan efektifitas instalasi pengolahaan air limbah diketahui parameter COD sebesar $70 \%$ dan Ammoniak sebesar 85,4\%,TSS sebesar 71.04\%,Phosphat sebesar 69,7\%.

Dari hasil pemeriksaan inlet pada instalasi pengolahan air limbah rumah sakit umum Muslimat Ponorogo masih cukup tinggi. pemeriksaan outlet instalasi pengolahan air limbah rumahsakit umum Muslimat Ponorogo mengalami penurunan.Dari efektivitas kerja IPAL RSU Muslimat Ponorogo efektif dalam menurunkan kadar pencemar akan tetapi masih melebihi nilai ambang batas yang sudah di tentukan

Saran yang dapat dianjurkan adalah mengoptimalkan jam operasional selama 24 jam, melakukan pemeriksaan air limbah secara rutin dan perawatan instalasi pengolahan air limbah untuk lebih di tingkatkan.
\end{abstract}

Kata Kunci : Efektivitas IPAL; Parameter (COD,Phosphat, TSS, Ammoniak dan pH.)

\section{PENDAHULUAN}

Rumah sakit sebagai salah satu unit dalam pelayanan kesehatan mempunyai fungsi utama dalam penyuluhan dan pemulihan. Rumah sakit perlu dikelola dengan baik dan benar, agar tidak menjadi sumber pencemaran lingkungan atau sumber penyakit. Untuk menunjang usaha tersebut antara lain dipergunakan Instalasi Pengolahan Air Limbah yang selalu berkembang mengikuti kemajuan teknologi, diperlukan pemilihan yang tepat dengan situasi dan kondisi. Sudah tentu Instalasi tersebut diharapkan dapat dipergunakan sebaik-baiknya, terpelihara dengan baik dan dapat mencapai batas waktu operasi, tidak menimbulkan bahaya-bahaya bagi para pasien, petugas, maupun masyarakat. Sesuai Undang-undang No. 23/1992 tentang Kesehatan, Rumah Sakit merupakan unit pelayanan kesehatan dan dapat diselenggarakan oleh pemerintah dan atau masyarakat. Dalam upaya pelaksanaan kesehatan, fungsi rumah sakit tidak dapat dipisahkan terhadap status kesehatan masyarakat dan kualitas lingkungan yang ada. Dengan kata lain bahwa keberadaan rumah sakit sebagai sarana pelayanan kesehatan diharapkan tidak mengganggu lingkungan yang ada sehingga terjadi penurunan kualitas lingkungan akibat pelayanan rumah sakit tersebut. Rumah sakit juga merupakan sumber penghasil limbah cair medis yang cukup besar, sehingga limbah cair yang dihasilkan dari kegiatan rumah sakit dapat menimbulkan gangguan kesehatan bagi masyarakat rumah sakit, yaitu petugas pelayanan dan pengunjung rumah sakit serta masyarakat sekitar rumah sakit. Sistem pengolahan limbah air bertujuan untuk menghilangkan atau menurunkan unsur-unsur pencemar 
dari limbah cair dan untuk mendapatkan efluen yang mempunyai kualitas yang dapat diterima oleh badan air (sungai) dan sesuai persyaratan yang berlaku agar lingkungan tidak tercemar (DEPKES RI, 1993). Pengolahan limbah cair terdiri dari kombinasi unit operasi dan unit proses yang didesain untuk mereduksi zat pencemar tertentu dalam limbah cair sampai batas yang dapat diterima. (Didik Sugeng Purwanto, 2006).

Rumah Sakit Umum Muslimat Kabupaten Ponorogo terletak di Jalan jend. A. Yani No.155 Ponorogo dan berada di tengah area permukiman penduduk. Banyaknya aktivitas di Rumah Sakit umum daerah akan menambah volume limbah cair. Limbah yang diolah dalam IPAL berasal dari semua unit di Rumah Sakit tersebut yaitu : dari ruang perawatan, ruang operasi, ruang linen, kamar mandi, toilet dan dapur.
Instalasi pengolahan air limbah rumah sakit umum daerah kabupaten Pacitan berdiri pada tahun 2007 dengan operasional dua puluh empat jam secara otomatis jika air limbah sudah penuh secara otomatis pompa penghisap akan beroprasi. Berdasarkan hasil pemeriksaan kimia dan fisika limbah cair RSU Muslimat di laboratorium Balai Besar Teknik Kesehatan Lingkungan Dan Pengendalian Penyakit (BBTKLPP) Surabaya bulan September 2013 kandungan parameter kimia COD 82,4 $\mathrm{mg} / \mathrm{l}$, Ammoniak sebesar 0,0940 mg/l TSS sebesar $9 \mathrm{mg} / \mathrm{l}$, Phosphat sebesar 9,35 mg/l, pH sebesar 7,5. Data ini menunjukkan bahwa parameter Phosphat dan COD melebihi nilai baku mutu PERGUB JATIM No. 72 Tahun 2013 Tentang Baku Mutu Air Limbah Bagi Kegiatan Rumah Sakit yaitu Phosphat sebesar 9,35 mg/l dan COD sebesar $82,4 \mathrm{mg} / \mathrm{l}$.

\begin{tabular}{|c|l|c|c|c|c|c|c|}
\hline No & \multicolumn{1}{|c|}{$\begin{array}{c}\text { Hari, Tanggal } \\
\text { Pemeriksaan }\end{array}$} & \multirow{2}{*}{ jam } & \multicolumn{5}{|c|}{ Inlet } \\
\cline { 4 - 8 } & & & $\mathrm{pH}$ & $\begin{array}{c}\mathrm{COD} \\
(\mathrm{mg} / \mathrm{l})\end{array}$ & $\begin{array}{c}\mathbf{P O}_{4} \\
(\mathrm{mg} / \mathrm{l})\end{array}$ & $\begin{array}{c}\mathrm{TSS} \\
(\mathrm{mg} / \mathrm{l})\end{array}$ & $\begin{array}{c}\mathrm{NH}_{3} \\
(\mathrm{mg} / \mathrm{I})\end{array}$ \\
\hline 1. & Senin, 8 Juni 2015 & 09.08 & 8 & 297,0 & 7,193 & 85 & 1,05 \\
\hline 2. & Selasa, 9 Juni 2015 & 10.07 & 8 & 237,6 & 6,985 & 90 & 1,51 \\
\hline 3. & Rabu, 10 Juni 2015 & 11.12 & 8 & 239,6 & 7,019 & 92 & 1,51 \\
\hline 4. & Kamis, 11 Juni 2015 & 11.09 & 8 & 261,4 & 6,427 & 82 & 1,80 \\
\hline 5. & Jumat, 12 Juni 2015 & 09.10 & 8 & 267,3 & 6,491 & 85 & 1,80 \\
\hline
\end{tabular}

\section{METODE PENELITIAN}

Penelitian ini adalah deskriptif karena akan melakukan deskripsi mengenai fenomena yang di temukan baik berupa faktor faktor resiko maupun hasil (Sastrosasmoro dkk199556) yaitu untuk mendapatkan efektivitas pengolahan air limbah dari inlet maupun outlet Dari Rumah Sakit Umum Muslimat Kabupaten Ponorogo Dalam penelitian ini menggunakan desain pretest dan protest. Adapun desain penelitiannya dapat digambarkan sebagai berikut :

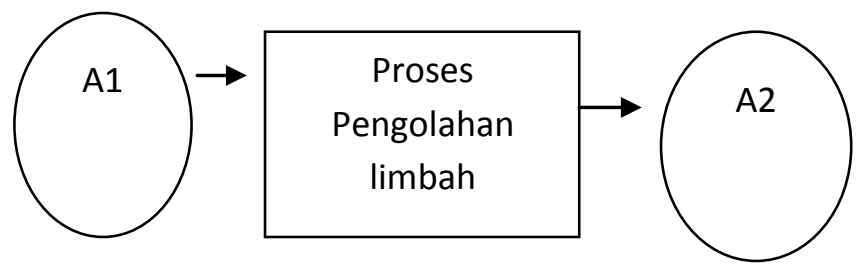

Gambar III. 1 Desain Penelitian

Keterangan :

$\mathrm{A} 1$ = Kadar COD, AMONIAK, TSS,PHOSPHAT,DAN pH sebelum proses pengolahan.

$\mathrm{A} 2=$ Kadar COD, AMONIAK, TSS, PHOSPHAT, dan $\mathrm{pH}$ setelah proses pengolahan

Teknik pengambilan sampel menggunakan teknik integrated sampel dimana sampel gabungan yang diambil secara terpisah dari beberapa tempat, dengan volume yang sama yaitu darioutlet IPAL Rumah Sakit Muslimat Daerah Kabupaten Paonorogo. Yang sedang dipantau. Sampel ini hanya menggambarkan. 


\section{HASIl PENELITIAN dan PEMBAHASAN}

1. Hasi Pemeriksaan Laboratorium sebelum proses pengolahan di IPAL

Tabel diatas menunjukkan hasil pemeriksaan laboratorium air limbah RSU Muslimat Ponorogoinlet maupun outletselama 5 hari berturut - turut mulai tanggal 8 Juni sampai 12 Juni 2015. Dari tabel tersebut dapat diketahui bahwa kadar beban pencemar COD (Chemical OxygenDemand), $\mathrm{NH}_{3}$ (Amoniak), TSS (Total suspended Solid), $\mathrm{PO}_{4}$ (Phosphat), $\mathrm{pH}$ (Potential of Hydrogen) mengalami penurunan setelah melalui proses pengolahan pada Instalasi Pengolahan Air Limbah.

Tabel 1

Hasil Pemeriksaan Laboratorium sesudah proses pengolahan di IPAL

\begin{tabular}{|c|l|c|c|c|c|c|}
\hline \multirow{2}{*}{ No } & Hari, Tanggal & \multicolumn{5}{|c|}{ Outlet } \\
\cline { 2 - 6 } & Pemeriksaan & $\boldsymbol{p H}$ & $\begin{array}{l}\text { COD } \\
(\mathbf{m g} / \mathbf{I})\end{array}$ & $\begin{array}{l}\boldsymbol{P O}_{\mathbf{4}} \\
(\mathbf{m g} / \mathbf{I})\end{array}$ & $\begin{array}{l}\text { TSS } \\
(\mathbf{m g} / \mathbf{I})\end{array}$ & $\begin{array}{c}\mathbf{N H}_{\mathbf{3}} \\
(\mathbf{m g} / \mathbf{I})\end{array}$ \\
\hline 1 & Senin, 8 Juni 2015 & 7 & 79,2 & 2,107 & 26 & 0,213 \\
\hline 2 & Selasa, 9 Juni 2015 & 7 & 74,3 & 2,172 & 28 & 0,241 \\
\hline 3 & Rabu, 10 Juni 2015 & 7 & 76,2 & 2,195 & 30 & 0,248 \\
\hline 4 & Kamis, 11 Juni 2015 & 7 & 79,2 & 1,893 & 20 & 0,174 \\
\hline 5 & Jumat, 12 Juni 2015 & 7 & 79,2 & 1,968 & 22 & 0,184 \\
\hline
\end{tabular}

Tabel diatas menunjukkan hasil pemeriksaan laboratorium air limbah RSU Muslimat Ponorogoinlet maupun outletselama 5 hari berturut - turut mulai tanggal 8 Juni sampai 12 Juni 2015. Dari tabel tersebut dapat diketahui bahwa kadar beban pencemar COD (Chemical OxygenDemand), $\mathrm{NH}_{3}$ (Amoniak), TSS (Total suspended Solid), $\mathrm{PO}_{4}$ (Phosphat),
$\mathrm{pH}$ (Potential of Hydrogen) mengalami penurunan setelah melalui proses pengolahan pada Instalasi Pengolahan Air Limbah.

2. Hasil Perhitungan Efektivitas kerja IPAL sesudah melalui proses Dalam Menurunkan Kadar Parameter Kimia

\begin{tabular}{|c|c|c|c|}
\hline \multirow{2}{*}{ No. } & \multirow{2}{*}{ Parameter Kimia } & \multicolumn{2}{|c|}{ Prosentase Rata-rata } \\
\cline { 3 - 4 } & & $\mathbf{m g} / \mathbf{I}$ & $\mathbf{\%}$ \\
\hline 1. & $\mathrm{COD}$ & 182,96 & 70 \\
\hline 2. & $\mathrm{NH}_{3}$ & 1,314 & 85,4 \\
\hline 3. & $\mathrm{TSS}$ & 61,6 & 71,04 \\
\hline 4. & $\mathrm{PO}_{4}$ & 4,74 & 69,7 \\
\hline 5. & $\mathrm{pH}$ & 7 & - \\
\hline
\end{tabular}

abel diatas menunjukkan hasil perhitungan efektivitas IPAL RSU Muslimat Ponorogo dalam menurunkan kadar beban pencemar COD, $\mathrm{NH}_{3}$, TSS, $\mathrm{PO}_{4}$, dan $\mathrm{pH}$ Dari tabel tersebut dapat diketahui bahwa kadar beban pencemar $\mathrm{COD}, \mathrm{NH}_{3}$ (Amoniak), TSS, $\mathrm{PO}_{4}$ (Phosphat), dan $\mathrm{pH}$ mengalami penurunan setelah melalui proses pengolahan pada Instalasi Pengolahan Air Limbah dengan efektivitas rata - rata sebesar $70 \%$, 85,4 \% , 71,04\%, dan 69,7 $\%$.

\section{ANALISIS HASIL PEMERIKSAAN LIMBAH CAIR PADA INLET dan OUTLET IPAL}

Hasil pemeriksaan laboratorium limbah cair yang diambil padainlet IPAL pada tanggal 8 Juni sampai dengan 12 Juni 2015, selama lima hari berturut - turut seperti tercantum pada tabel IV.5 dapat dianalisa sebagai berikut :

1. Analisa

COD

(ChemicalOxygenDemand)

Hasil perhitungan rata-rata COD pada reactorinlet $260,58 \mathrm{mg} / \mathrm{l}$ dan pada reactoroutlet adalah $77,62 \mathrm{mg} / \mathrm{l}$. Efektivitasnya sebesar 70\%.Menurut Marsono efektivitas removal COD adalah 90-95 \%. Sehingga dapat dikatakan bahwa kondisi IPAL Rumah Sakit Muslimat Ponorogo belum maksimal dalam mengolah limbah cair sehingga memungkinkan untuk timbul pencemaran bau pada outlet IPAL.

2. Analisa $\mathrm{NH}_{3}$ (Ammoniak)

Hasil perhitungan rata-rata $\mathrm{NH}_{3}$ pada reactorinlet $1,526 \mathrm{mg} / \mathrm{l}$ dan pada 
reactoroutlet adalah $0,212 \mathrm{mg} / \mathrm{l}$. Efektivitasnya sebesar $70 \%$. Menurut Marsono efektivitas removal $\mathrm{NH}_{3}$ adalah 90-95\%. Sehingga dapat dikatakan bahwa kondisi IPAL Rumah Sakit Muslimat Ponorogo belum maksimal dalam mengolah limbah cair sehingga memungkinkan untuk timbul pencemaran bau pada outlet IPAL.

3. Analisa TSS(Total Suspended Solid) Hasil perhitungan rata-rata TSS pada reactorinlet $86,8 \mathrm{mg} / \mathrm{l}$ dan pada reactoroutlet adalah 25,2. Efektivitasnya sebesar $71,1 \% \mathrm{mg} / \mathrm{l}$. Menurut Marsono efektivitas removal TSS adalah 90-95 \%. Sehingga dapat dikatakan bahwa kondisi IPAL Rumah Sakit Muslimat Ponorogo belum maksimal dalam mengolah limbah cair sehingga memungkinkan untuk timbul pencemaran bau pada outlet IPAL.

4. Analisa $\mathrm{PO}_{4}$ (Phosphat)

Hasil perhitungan rata-rata $\mathrm{PO}_{4}$ pada reactor inlet $6,82 \mathrm{mg} / \mathrm{l}$ dan pada reactor outlet adalah $2,06 \mathrm{mg} / \mathrm{l}$. Efektivitasnya sebesar 69,7\%. Menurut Marsono efektivitas removal $\mathrm{PO}_{4}$ adalah 90-95 \%. Sehingga dapat dikatakan bahwa kondisi IPAL Rumah Sakit Muslimat Ponorogo belum maksimal dalam mengolah limbah cair sehingga memungkinkan untuk timbul pencemaran bau pada outlet IPAL.

5. Analisa pH (Potential of hidrogen) Hasil perhitungan rata-rata $\mathrm{pH}$ pada reactorinlet 8 dan pada reactoroutlet adalah 7.

\section{ANALISA DAMPAK}

Kondisi IPAL yang kurang baik ini sebaiknya ditimgkatkan agar kadar beban pencemar pada efluen berada dibawah batas maksimum yang dipersyaratkan. Apabila kondisi IPAL yang tidak baik ini tidak segera diperbaiki maka dapat terus menurunkan kualitas efluen limbah cair pada outlet IPAL dan mecemari lingkungan sekitar.

Dampak yang ditimbulkan akibat tingginya kadar beban pencemar COD, $\mathrm{NH}_{3}$, TSS, $\mathrm{PO}_{4}$, dan $\mathrm{pH}$ pada efluen IPAL Rumah Sakit Muslimat Ponorogo adalah dampak langsung dan tidak langsung.

\section{ANALISA PENYEBAB}

Semua kadar beban pencemar dalam efluen limbah cair pada outlet IPAL berada dibawah nilai baku mutu. Hal ini menunjukkan IPAL berfungsi sesuai dengan tujuan yang diharapkan. Sebab sebab turunnya kadar beban pencemar dalam limbah cair pada IPAL Rumah Sakit
Umum Muhammadiyah Diponegoro Ponorogo sebagai berikut :

1. Faktor Teknis

Faktor teknis adalah faktor yang berkaitan dengan sistem pengolahan limbah cair yang mempengaruhi keefektivitasan IPAL Rumah Sakit Muslimat Ponorogo dalam menurunkan parameter $\mathrm{COD}, \mathrm{NH}_{3}$, TSS, $\mathrm{PO}_{4}$, dan $\mathrm{pH}$.

2. Faktor Non Teknis

a. Biaya

Biaya operasional dan pemeliharaan IPAL melalui usulan/proposal dana yang diajukan setiap tahun dapat keluar jika permasalahan sangat urgen dan berdampak luas. Hal ini mengakibatkan apabila terjadi kerusakan-kerusakan pada unit-unit.

b. Manusia

Terbatasnya jumlah sumber daya manusia yang mempunyai latar belakang bidang kesehatan lingkungan. Seorang sanitarian harus mengangani seluruh aspek kesehatan lingkungan di rumah sakit, mulai dari penyediaan air bersih, pengelolaan sampah (medis dan non medis), penyehatan ruangan dan bangunan, pengendalian vector dan binatang pengganggu dan lain-lain.

\section{KESIMPULAN}

1. Hasil pemeriksaan kadar beban pencemar pada air limbah sebelum proses pengolahan diIPAL Rumah Sakit Muslimat Ponorogo adalah tinggi.

2. Hasil pemeriksaan kadar beban pencemar pada air limbah sesudah proses pengolahan di IPAL Rumah Sakit Muslimat Ponorogo adalah turun. Jadi kadar kelima bahan pencemar mengalami penurunan setelah melalui proses pengolahan limbah namun masih melebihi baku mutu yang ditentukan. Kadar pencemar yang tidak memenuhi syarat adalah $\mathrm{NH}_{3}$ (Amoniak) dan $\mathrm{PO}_{4}$ (Phosphat)

3. Hasil perhitungan efektivitas rata-rata IPAL Rumah Sakit Muslimat Ponorogo dalam menurunkan kadar beban pencemar dalam air limbah yaitu Instalasi Pengolahan Air Limbah Rumah Sakit Muslimat Ponorogo tidak efektif menurunkan kadar beban pencemar dari parameter kimia yaitu $\mathrm{COD}, \mathrm{NH}_{3}$, TSS, $\mathrm{PO}_{4}$ dan $\mathrm{pH}$.

\section{SARAN}

1. Blower dinyalakan selama 24 jam dan ditambah jumlahnya agar dapat mengurangi beban pengolahan pada 
reaktor selanjutnya. Sehingga kualitas efluen yang sudah baik semakin meningkat.

Tambah reactor penangkap lemak grease trap, karena lemak akan mengapung dan membeku pada suhu $20^{\circ} \mathrm{C}$ sehingga memudahkan pembersihan secara berkala dan mekanik. Lemak atau minyak yang tidak ditangkap/langsung dilarikan pada pengolah berikutnya, mengakibatkan matinya mikroorganisme karena terjadi proses pembusukan sehingga berbau.

2. Pengolahan sebelum dibuang ke proses aerasi limbah cair dapat diberikan Bak sisa klor agar pencemaran limbah berkurang.Bak ini berfungsi sebagai desinfeksi pada pengolahan limbah cair.

\section{DAFTAR PUSTAKA}

Anonimous,http://repository.usu.ac.id/bitst ream/123456789/38754/4/Chapter\% 20II.pdf, 21 January 2015, 21.05

Anonimous.http://renidewitasari.blogspot.c om/2013/11/senyawa-aromatikfenol.html,21 January, 23.27

Anonimous, 1993. Pedoman Pemeliharaan Instalasi Pengolahan Limbah Cair Rumah Sakit. DEPKES RI.

Anonimous, 2001. Kamus Besar Bahasa Indonesia Edisi Ketiga. Jakarta. Balai Pustaka

Asmadi, 2013. Pengelolaan Limbah Medis Rumah Sakit. Yogyakarta. GosyenPublishing

Djabu, Udin dkk, 1990/1991. Pedoman Bidang Studi Pembuangan Tinja Dan Air Limbah Pada Institusi Pendidikan Sanitasi/Kesehatan Lingkungan. Jakarta. DEPKES RI.

G. Alaerts, Sri SumestriSantika. 1987. MetodaPenelititan Air. Surabaya. Usaha Nasional.

Jati, Waluyo dkk. 1981. Dasar - dasar Penyediaan Air Minum. Surabaya. Sekolah Pembantu Penilik Surabaya.

Keputusan Menteri Negara Lingkungan Hidup Nomor 58 Tahun 1995 Tentang Baku Mutu Limbah Cair Bagi Kegiatan Rumah Sakit

Khiatuddin, Maulida. 2003. Melestarikan Sumber Daya Air Dengan Teknologi Rawa Buatan. Yogyakarta. Gadjah Mada University Press

Marsono, Bowo Joko. Teknik Pengolahan Air Limbah Secara Biologis. Surabaya.
Upaya yang dapat dilakukan adalah pengolahan sebelum dibuang ke proses aerasi limbah cair dapat diberikan sisa klor agar pencemaran limbah berkurang.

3. Monitoring pada efluen IPAL tetap rutin dilakukan setiap 1 bulam sekali agar penurunan kualitas efluen segera diketahui, sehingga kerusakan atau gangguan yang menyebabkan ketidakoptimalan fungsi IPAL tersebut dapat segera evaluasi perbaikan.

4. Bagi Peneliti Lain

Perlu dilakukan penelitian mengenai efektivitas masing-masing reaktor IPAL untuk mengetahui reaktor yang berfungsi kurang optimal.

Media Informasi Alumni Teknik Lingkungan ITS.

Mohammad Razif, Adhi Yuniarto. 2004. Pengelolaan Kualitas Air. Surabaya. Intsitut Teknologi Sepuluh Nopember

Nurhamidah, Subhania Fahmi. 2010. Studi Tentang Efektivitas IPAL Rumah Sakit Griya Husada Madiun Dalam Menurunkan Kadar BOD. Jurusan Kesehatan Lingkungan Magetan.

Notoatmojo, Soekidjo. 2005. Metodologi Penelitian Kesehatan. Jakarta. Rineka Cipta.

Peraturan Gubernur Jawa Timur Nomor 72 Tahun 2013 Tentang Baku MutuAir Limbah Bagi Kegiatan Rumah Sakit.

Trimarjono,SH, 1990. Biro Tentang Baku Cara Uji Air Dan Air Limbah Di Jawa Timur Bina Kependudukan dan Lingkungan Hidup Sekretariat Wilayah /Daerah Tingkat Jawa timur.

Purwanto, Didik Sugeng, 2004. Pengelolaan LImbah Cair Teori Praktis untuk Calon Tenaga Sanitasi. Surabaya. Jurusan Kesehatan Lingkungan - Poltekkes Surabaya.

Purwanto, Didik Sugeng, 2006. Pengolahan Limbah Cair. Surabaya. Dua Tujuh.

Rohmawati, Anisatur. 2011. Efektivitas Pengolahan Air Limbah Di PT. Carma Wira Jatim Pabrik Kulit Magetan. Jurusan Kesehatan Lingkungan Magetan.

Sigit Gunawan, Sunaryo, ShantiSetyorini, 2012. Pedoman Praktek Laboratorium Prodi D III Kesehatan Lingkungan Kampus Magetan. Magetan. 